\title{
EL PODER DE LA PALABRA Y LA FE EN LA CURACIÓN DENTRO DEL CONTEXTO CULTURAL GALLEGO
}

\author{
Por \\ ROSA GARCÍA-ORELLÁN
}

\section{RESUMEN}

En este trabajo muestro los «pactos» que se realizan en los procesos de curación donde se establece un diálogo con nuestro mundo de creencias.

Las acciones rituales encaminadas a la curación abarcan el conjunto del rito propiamente dicho, en él se dinamiza el eje signo=enfermedad/ símbolo=lugar donde se deposita la misma.

La estructura del diálogo se muestra en el estudio intergeneracional aquí analizado, el cual nos permite constatar aquellos elementos de transmisión que siguen vigentes así como los cambios que aquí mostramos.

\section{PALABRAS CLAVE}

Fe, simbolismo representado, simbolismo figurado, esotérico, exotérico.

\section{ABSTRACT}

I show in my piece of work the «pacts» that take place in the healing process, in which a dialogue is established with our world of personal

«CUADERNOS DE ESTUDIOS GALLEGOS», Tomo L, Fascículo 116, Santiago 2003. 
beliefs. Ritual actions directed to desired healing include the whole ritual as such. In this stage the axis sign=sickness / symbol=place in which illness is being deposited.

Dialogue structure is shown in the intergenerational study shown here, which allow us to identify those transmission elements actually in place as well as those changes involved.

\section{KEYWORDS}

Faith, represented symbolism, figurative symbolism, esoteric, «exoteric», that is, of easy comprehension (opposite to esoteric).

\section{INTRODUCCIÓN}

La enfermedad es una señal de alarma en la que nuestro cuerpo físico muestra su vulnerabilidad activando en nosotros la finitud del tiempo de nuestra corporeidad. Este trabajo se va a centrar en los «pactos» que se realizan en los procesos de curación.

Tanto la enfermedad como la muerte dinamizan al colectivo social, comenzando por el grupo doméstico. A este respecto el antropólogo Rafael BRIONES GÓMEZ ${ }^{1}$ establece la existencia de un itinerario terapéutico en el que se hallan implicados los grupos primarios que rodean al paciente. En un momento u otro aparece un recurso a lo religioso, bien sea en la medicina popular o en la medicina científica. Esta es la realidad constatada por el autor, en este trabajo me baso en los procesos curativos tradicionales; en ellos, el elemento de la fe, que lleva a la creencia de que se va a producir la curación y su ritual correspondiente, forman los dos elementos que constituyen de forma unitaria la resolución del estado de enfermedad a la salud.

\footnotetext{
${ }^{1}$ Artículo publicado en Medicina popular e antropología da saúde. Simposio internacional en homenaxe a A. Fraguas Fraguas. Ed. Consello de Cultura Galega. Santiago, 1997 Título del artículo: «El recurso a lo religioso en el itinerario terapéutico» (1997) pág. 197-219.
}

«CUADERNOS DE ESTUDIOS GALLEGOS», Tomo L, Fascículo 116, Santiago 2003. 
Como principio metodológico parto de los relatos biográficos, trabajados en el contexto cultural gallego, durante los años 1998-1999, centrado básicamente en dos parroquias coruñesas: la de Olveira y la de Corrubedo, en las que se da una forma de curación donde la enfermedad sale del cuerpo.

En el proceso curativo veremos sobre todo el simbolismo representado simplemente, o bien este junto con la acción simbólica donde se encuentra la palabra, pero también se da el simbolismo figurado. Tanto el simbolismo representado como el simbolismo figurado los expresa el antropólogo Louis VINCENT-THOMAS en los siguientes términos:

La expresión simbólica puede aprehenderse en dos planos: el símbolo representado y el símbolo figurado.

VINCENT-THOMAS, Louis (1993): 548

Ambos simbolismos constituyen los elementos constitutivos de la curación. Para ello el elemento de la fe es decisivo en la misma.

Comenzaremos señalando la percepción de la enfermedad guiados de la mano del Maestro humanista Michel de MONTAIGNE (1533/1592) en su obra Essais livre III, (1965).

Et que la santé d'où nous partîmes était telle qu'elle soulage ellemême le regret que nous en devrions avoir. C'était santé, mais non qu'à la comparaison de la maladie qui l'a suivie.

\section{MONTAIGNÉ, Michel (1965): 332}

Esta profunda reflexión, que nos muestra cómo se percibe la enfermedad en función de la salud, es de suma importancia, puesto que es un elemento estructural de nuestra especie, en la que la dualidad existe en función de la unidad. Y para el antropólogo Claude LÉVI-STRAUSS, el binarismo constituye uno de los ejes más fundamentales del pensamiento antropológico y atraviesa diagonalmente toda su obra. Lo voy a expresar con sus propias palabras, tomadas de: Mithologiques Le Cru et le Cuit 1964.

Il ne suffit donc pas de dire que, dans ces mythes, la nature, l'animalité, $s$ 'inversent en culture et en humanité. La nature et la culture, l'animalité et l'humanité, y deviennent mutuellement perméables. D'un règne à 
l'autre règne, on passe librement et sans obstacle: au lieu qu'un fossé existe entre les deux, ils se mêlent au point que chaque terme d'un des règnes évoque aussitôt un terme corrélatif dans l'autre règne, propre à le signifier comme il le signifie en retour.

LÉVI-STRAUSS, Claude (1964): 281

La naturaleza existe en contraposición a la cultura. Una se percibe en función de la otra. Pero a su vez ambas no constituyen dos elementos opuestos, sino como bien señala el autor, de una a otra se pasa de forma correlativa. También apunta que ambas existen en una unidad. Es así como sucede en la transposición de un signo a un símbolo, insertados en la realidad binaria salud/enfermedad, que en este estudio se realizará sacando la enfermedad del cuerpo.

Partiendo de este principio el antropólogo Joxemartin APALETEGI BEGIRISTAIN amplía el binarismo de LEVI-STRAUSS, expuesto en los mitos y lo explicita en la tradición oral de los kontuzaharrak = cuentos viejos de la comunidad rural gipuzkoana de Ataun. En mi exposición, el análisis ritual se halla en la oralidad de los relatos biográficos de mis informantes, vividos por ellos mismos y recogidos en un momento actual de cambio en las comunidades rurales. Estas acciones rituales caminan hacia la oralidad narrada sin la vivencia ritual de los mismos.

Lo que a continuación expongo, en el momento de realizar esta investigación, ha pasado de ser una acción comunitaria a realizarse en situaciones individuales excepcionales.

Los rituales de curación se pueden producir en dos niveles. Primer nivel: realizando una transposición binaria de un signo, lugar donde se ubica la enfermedad, a un símbolo que es el lugar donde se traslada la enfermedad. Ésta sale, por lo tanto, del cuerpo y se soluciona la situación. Segundo nivel: también se realiza la transposición binaria, pero con esta variante: en este caso el paso del signo al símbolo precisa estar enmarcado en un rito determinado, junto a la acción de la Palabra. Ésta puede ser esotérica o exotérica.

Existen dos tipos de transmisión de la Palabra en los rituales de mis contextos por mí estudiados y claramente diferenciados: las palabras rituales esotéricas y las palabras rituales exotéricas. Ambos conceptos los voy a exponer tal y como los recoge María MOLINER EN El Diccionario de uso del español 1994. 
esotérico, -a. (Gr. "esoterikós», de "eso», adentro; v. "exotérico».) *Oculto o *secreto: no a la vista de todos o no asequible a todos, sino sólo a los iniciados.

MARIA MOLINER1994: 1196

Las palabras que se pronuncian en el ritual y que son esotéricas son transmitidas generalmente en el seno de los grupos domésticos. En el caso de quitar o aire pertenece el ritual al ámbito femenino, se transmite de madre a hija siempre que ésta tenga «el don», es decir, que pueda recibir realmente las palabras y para ello lle ten que dar a alma a su madre.

En caso de que la hija no las pueda recibir, se las transmitirá bien a la siguiente generación o incluso pueden ser dadas a un miembro que no sea del grupo doméstico propio. Pero es muy importante que la persona que las reciba esté realmente capacitada para ello, puesto que, de lo contrario, las palabras perden a virtud y la persona que las recibe las olvida inmediatamente.

En la parroquia de Olveira, (Coruña), más concretamente en la aldea de Bretal, la casa de Montemuiño va a ser el lugar de referencia para sacar o aire durante todo este siglo veinte. Y esto lo harán la abuela, la madre y las hijas. La transmisión queda en la nieta, que vive actualmente en la Coruña. Respecto a este ritual constato únicamente casos de mujeres sanadoras.

El hecho de transmitirlo es un acto que tiene que ser previamente reflexionado por la persona que lo da, puesto que no se puede estar dando las palabras de forma aleatoria. Pues de ese modo se perdería la virtud de la palabra, es decir, su poder.

Dichas palabras no deben ser escritas, solo se deben mantener en la oralidad. Lo voy a exponer con el propio testimonio de la sanadora tía Juanita de Montemuiño, de setenta y siete años y de su grupo doméstico, recogidos por mí en el documento etnográfico Pablo-Enea 1999.08.09,113:29, transcripción de la grabación realizada en Bretal 1999.07.21,3$15: 30$.

A nora: Quen non o aprende a primeira vez, é que non está preparado para aprendelo.

Tía Juanita: Si meus fillos o que non aprende da primeira xa nada. 
Francisco: $O$ malo é que todo vai por palabras, a paletilla por palabras, ela sábeo ben, só pódese decir unha vez porque senón esquécese. Tía Juanita: Nós temos aquilo.

GALIZA INFORMANTES 1999: 25,26

En caso de que a una persona le repitas las palabras, se olvidan. No se pueden decir más que una vez a una persona. Si las palabras hacen eco en ella y son retenidas, significa que ha cogido la transmisión.

Como esotérico en mis contextos estudiados, se consideran las palabras correspondientes al ritual de quitar o aire, bien sea de animal, mujer o difunto, así como levantar a paletilla. Es así como lo realizan en Bretal, aldea perteneciente a la parroquia de Olveira (Coruña). No obstante, el antropólogo Xosé Ramón MARIÑO FERRO en su libro La medicina popular interpretada II,1986, ofrece un amplio estudio donde va indicando las palabras rituales recogidas en distintos puntos de la geografía gallega, y relacionados con levantar a paletilla. En mi contexto doy testimonio de que dichas palabras rituales, en ambos aspectos, solamente pertenecen al ámbito esotérico.

En segundo lugar están los rituales exotéricos, cuyas palabras se dicen en voz alta, y circulan entre los miembros de la aldea. El término de exotérico lo expongo según el Diccionario de Uso del español 1992 de Maria MOLINER:

exotérico, -a. (Formado con «exo», paralelamente y a imitación de «esotérico»-véase-.) Asequible a la generalidad de la gente. ( $V$. «*PÚBLICO».)

MARIA MOLINER: 1256

En mis contextos, los rituales cuyas palabras sean exotéricas, son los correspondientes a quitar as beloiñas.

«CUADERNOS DE ESTUDIOS GALLEGOS», Tomo L, Fascículo 116, Santiago 2003. 


\section{TRANSPOSICIÓN BINARIA DEL SIGNO AL SÍMBOLO MEDIANTE LA ACCIÓN RITUAL EN LA QUE SE INCLUYE LA PALABRA}

En esta transposición binaria desarrollaré las acciones de quitar o aire, levantar a paletilla, curar as beloínas, siguiendo la reflexión de Edmund LEACH, en su libro Cultura y Comunicación. La lógica de la conexión de los simbolos, 1993 (título original: Culture and communication. The logic by wich symbols are connected, 1976).

Los indicadores en los sistemas de comunicación no verbales, al igual que los elementos sonoros en la lengua hablada, no tienen significación aislados, sino solo como miembros de conjuntos. Un signo o símbolo sólo adquiere significación cuando se le diferencia de algún otro signo o símbolo opuesto.

LEACH, Edmund (1993): 65

Partiendo del binomio salud/enfermedad realizamos la transposición de un signo, lugar donde va a estar situada la enfermedad, a un símbolo opuesto que se halla en la salud. El trasfondo de la relación ritual es binaria y la significación del mismo se halla en la acción ritual junto con la creencia en la misma.

\section{1.- «QUITAR O AIRE»}

\subsubsection{En la parroquia de Olveira-Coruña-Casa de Montemuiño}

En la parroquia de Olveira es la casa de Montemuiño, de la aldea de Bretal, el lugar de referencia para quitar o aire, si bien existe otra casa en la que también se sacará el aire, expondré ambas con sus diferencias rituales.

\subsubsection{Tipos de aire}

El aire puede ser de mujer, animal o difunto. De los tres, el más peligroso y costoso de quitar es el del difunto, el cual lo tengo investigado en mi artículo Action face à deux rencontres liminales: celle du défunt, de son statut à l'enterrement, et quelques situations des vivants, enviado a la revista Anthropophage de 1' E.H.E.S.S. en Paris, Febrero del 2000. En el mismo realizo un análisis sobre la transgresión que se produce ante el encuentro del difunto y ciertas situaciones de los vivos, como son las 
mujeres embarazadas y los niños. En este trabajo no desarrollaré «el aire de los difuntos».

En primer lugar, voy a establecer los elementos estructurantes respecto a quitar o aire, los cuales no necesariamente se presentan en todas las acciones simbólicas del ritual. Incluso, constato dos actos en los que se va a dar un único elemento estructrurante del mismo: uno de ellos desarrollado en el punto 1.1.3. y el segundo lo desarrollo en el punto 1.1.4. A continuación enumero los siguientes elementos rituales estructurantes:

Delimitar un TIEMPO ritual mediante un número. Puede ser el nueve o el tres.

Sacralizar un ESPACIO durante el tiempo ritual: la casa, la encrucijada.

Nombrar unas PALABRAS.

En los rituales que expongo a continuación, la delimitación de los mismos en un tiempo/espacio es un elemento estructurante que abarca a todo tipo de rituales. Sin embargo, la expresión de las palabras puede darse de forma aleatoria.

\subsubsection{Síntomas fisiológicos para acudir a «quitar o aire»}

Antes de proceder a quitar o aire del niño, éste debe presentar unos síntomas. Sigo las propias palabras de tía Juanita de Montemuiño, de setenta y siete años, que es la mujer que quita o aire en la parroquia de Olveira, y que están recogidas en el documento etnográfico Casa d'Agra 1999.07.22,4-10:10. Transcripción da grabación realizada o miércoles 1999.07.21,3.15:30:

Tía Juanita: Aquí chegaba a criatura ou súa nai con ela, ou si era grandiño xa igual viña él soliño, ben, chegaba aquí, desnudábase e ollaba as perniñas e mais os braziños ruchadiños.

GALIZA INFORMANTES 1999: 15

En la casa de Montemuiño se produce un cambio en la interpretación del diagnóstico a lo largo de este siglo veinte. Tía Juanita de Montemuiño diagnostica que realmente el niño tiene $o$ aire porque tanto los brazos

«CUADERNOS DE ESTUDIOS GALLEGOS», Tomo L, Fascículo 116, Santiago 2003. 
como las piernas están ruchadiñas ${ }^{2}$. Sin embargo para su sobrina Isabel de Montemuiño, el diagnóstico adquiere matices diferentes. Para ello citaré en primer lugar a C.G. JUNG en su obra Tipos Psicológicos 1994, (título original Psychologische Typen 1971).

Mientras un símbolo está vivo es la expresión de una cosa que no cabe designar de mejor manera que con él. El símbolo sólo está vivo mientras se halla preñado de significado. Pero si el símbolo ha dado a luz su sentido, esto es, si ha sido encontrada la expresión que formula mejor que el símbolo usado hasta ese momento la cosa buscada, aguardada o presentida, entonces el símbolo muere, es decir ya no tendrá más que un significado histórico.

JUNG, C.G (1994): 555

Va a ser la última generación de la casa de Montemuiño quien confiera a toda la simbología del ritual «un significado histórico» de carácter junguiano. A continuación, lo expondré con su propio testimonio.

\subsection{La Transmisión de "quitar o aire», en la generación naci- da en la década de los años mil novecientos cincuenta}

Isabel de Montemuiño nace a mediados de los años cincuenta. Tanto su madre como su abuela y su tía sacaban o aire de los niños. Actualmente vive en Coruña, si bien conserva la casa de su madre en Bretal. Voy a señalar cómo ve ella el hecho de ter o aire. Recogido en el documento A.Pablo-Enea 1999.08.10,2-10:32

Eu: ¿Qué era o aire?.

Maria Isabel: Debia ser un parásito dos animais, non habia as vacinacions adecuadas, e parece que collian unha especie de morriña, moi desmellorados, moi mal, adelgazaban moitísimo, eu acórdome que iban moi delgadiños. Eu a simple vista xa os coñecía, non fai falta tocarlles nada. Miña abuela cando estaba de mal xenio non era nada sociable, eu recordo que unha familia a votou a fume de carozo por-

${ }^{2}$ RUCHADIÑO: sinónimo de «consumido» término utilizado de forma metafórica dentro de los giros lingüístico de la aldea de Bretal, significa delgadez enfermiza.

«CUADERNOS DE ESTUDIOS GALLEGOS», Tomo L, Fascículo 116, Santiago 2003. 
que era moito traballo ¿entendes?, estaban na recolleita e había moito traballo e moitos fillos pero, bueno, a señora foi perseverante $e$ conseguiuno. Mi madre ten quitado moitísimo e de persoas contaba poucos casos, o que máis era de animal, é dificil saber se é de can ou de gato. Isto é o que máis hai. O meniño pasaba para a cociña e despois poñianse na ventana a abrir a bóla e eu téñoo visto. Ahora perdeuse xa non ten obxecto, xa non existe.

Eu: Pois ainda estano sacando oxe en día, ainda está en vigor. ¿En vós pérdese entón?.

Maria Isabel: Xa non ven ninguén a pedilo, miña aboa as veces non quería, e a miña nai dáballe pena e por eso ela o aprendeu.

Eu: ¿Na túa familia pérdese?.

María Isabel: Ahora ninguén ven tampouco, eu penso que agora xa non ten obxecto.

GALIZA INFORMANTES 1999: 5

\subsection{Cambio intergeneracional en la concepción de "Qué é o aire»}

Mencionaré a continuación algunas de las características fundamentales que distingo en el testimonio que mi informante Maria Isabel me proporciona a requerimiento mío:

1.- Respecto a qué é o aire, Maria Isabel intenta dar una respuesta concreta diciendo: que debía ser un parásito de los animales, no había las vacunas adecuadas, adelgazaban muchísimo..

Esta asociación do aire a un parásito la expondrá tanto Maria Isabel como mi otra informante Gelucha, pertenecientes a la aldea de Bretal, siendo ambas de la misma generación. Sin embargo, la anterior generación, la nacida en los años treinta, no asocia $o$ aire a parásitos intestinales. $O$ aire es un elemento abstracto que transmiten las hembras de los animales cuando «están de alta», el difunto o la mujer que está con fluidos menstruales o puerperales.

2.- Presenció en su infancia muchos rituales de quitar o aire, la mayoría de ellos de aire animal.

3.- Según María Isabel, actualmente ya nadie acude a realizar estos rituales porque ya no tiene sentido hacerlos. Ella percibe de su gru- 
po social que éste ya no cree de forma mayoritaria en este tipo de ritual. Con ello se cumple el tercer punto que señala Lévi-Strauss con relación a los procesos curativos: la necesidad de la creencia del ritual en el colectivo social

El denominador común intergeneracional para declarar que un niño tiene $o$ aire es su extrema delgadez. Lo que cambia es la interpretación que se hace de esa delgadez.

\subsubsection{Diagnóstico para conocer el tipo de aire}

He aquí las características que he encontrado en mi análisis del diagnóstico para conocer el tipo de aire:

1. En la parte del proceso ritual de quitar o aire que se realiza en la casa, va a ser en la bola de borralla $^{3}$ donde se va a posibilitar una doble función: la de ser a la vez elemento diagnóstico y curativo en caso de que «el aire» sea de mujer o de animal, pero no será curativo en caso de que «el aire» sea de difunto.

2. Reforzarmiento del ritual, pasando el niño por debajo de San Migueliño (santo que se encuentra en la iglesia parroquial de XuñoCoruña, a unos quince kms. de la parroquia de Olveira).

3. En caso de que el niño, además de tener «o aire» "esté atado», tendrá que ir a una encrucijada de caminos a las doce de la noche.

\subsection{Desarrollo ritual de "Quitar o aire» en casa}

Recogido en el documento arriba indicado. Narrado por tía Juanita de Montemuiño, que es la persona que «saca o aire». Elaboración «das borrallas» y diagnóstico de las mismas.

Tía Juanita: Aqui chegaba a criatura ou súa nai con ela, ou se era grandiño xa igual viña el soliño, ben, chegaba aqui, espíase e ollaba as perniñas e mais os braziños ruchadiños, moi ben, ben, pois tal día

\footnotetext{
${ }^{3}$ BORRALLA: (según el diccionario normativo Galego-Castelán 1988).- Ceniza, polvo gris resultante de quemar completamente una cosa. En este contexto ritual, la bola de borralla es el resultado de la cocción de la ceniza, lo expongo detalladamente más adelante.
}

«CUADERNOS DE ESTUDIOS GALLEGOS», Tomo L, Fascículo 116, Santiago 2003. 
ou tal día, que a borralla hai que queimala e non pode ser borrallada desa. Teñen que ser brancas, e despois de queimadiña e morta no lume pásala por un baruto.

Eu: ¿Que é un baruto?.

Francisco: Unha peneira moi fina, moi fina.

Tía Juanita: Hay que pasar a borralla por unha peneiriña, o día que penses de o sacar.e a dona da casa quéimaa na lareira, sen lle botar papeis nin nada.

Eu: ¿Que é o que queima?.

Tía Juanita: Os carozos.

Eu: ¿Uns carozos de millo?

Tía Juanita: Si, ata que estea feita e despois de que estea feita xúntase ben xuntiña para que ninguén ande alí, e ten que morrer ata que morra o lume todo... hai que deixar morrer o lume. Ó estar os carociños queimadiños, vas botando a moreíña, barutada.

Francisco: Non son os carozos Juanita, son as bridas de vide...é a brida a que fai a borralla moi branca, ainda que sexa brida negra fai a borralla branca.

Tía Juanita: ..nós xa as temos tamén feito, pero botas os carozos e as bridas, nós cando había as bridas faciámola coas bridas nada máis.

Eu: ¿Podía ser tanto de día como de noite?.

Tía Juanita: Non podía ser de noite, tiña que ser de día, non lle decías nada a ninguén, e podía ser a hora que ti quixeras... a borralla barutadiña botaba sete dias. E botabala a unha oliña de auga, ata que estivera cocida.

Eu: ¿Haina que votar cando ferva a auga?.

Tía Juanita: Cando ferva a auga un anaco botas a borralla...vas remexendo seguido, remexendo seguido e despois ó que está cocidiña...»

Ibid: $15-16$

Esta exposición recoge todo el proceso de elaboración de la borralla antes de proceder a la aplicación de la misma sobre la persona.

1. Previa a la elaboración de la borralla, la lareira (el hogar) ha de estar barrida y limpia.

«CUADERNOS DE ESTUDIOS GALLEGOS», Tomo L, Fascículo 116, Santiago 2003. 
2. Para la elaboración de la borralla se pueden utilizar únicamente las bridas blancas o negras de la viña y si ya quedan pocas bridas se puede elaborar también la borralla con los carozos del maíz.

3. Insistencia en que las cenizas estén completamente apagadas.

4. La ceniza puede durar un máximo de siete días.

5. Para hacer la bola hay que echar la ceniza en agua hirviendo, removiéndola hasta que quede una masa espesa. Luego se retira una bola de la misma colando el agua de la ceniza.

- Procedimiento sobre la persona:

En todo este proceso $o$ aire que produce la enfermedad en la persona es un signo, el cual, si es de mujer o animal hembra, pasará a la «bola de borralla», que es un símbolo. Dicho paso, del signo al símbolo, se realiza mediante una acción simbólica, estando todo ello incluido en un acto ritual.

Establezco una auténtica Unidad entre el símbolo y la acción simbólica. Ambos tienen el mismo potencial de activación para que el aire salga realmente del signo, que es la persona, a la «bola de borralla». El aire no puede salir sin la acción ritual, puesto que, además del simbolismo externo, se encuentra un simbolismo interno en las palabras que son nombradas. Éstas no pueden decirse en voz alta puesto que son esotéricas y «perderían la virtud».

He aquí las propias palabras de tía Juanita de Montemuiño:

Tía Juanita: E a criaturiña...eu póñoa asi (enriba das súas pernas, a criatura co cu para enriba a cabeza para a esquerda e os pés a dereita), cou barutiño de vez en cando remexendo, dis o que tes que decir, (en voz baixa), e empezas a mollar e remexer, contas nove veces sin te enganares, volver a remexer, empezando sempre de forma para dentro dos peíños.

Eu: ¿Sempre empezas das esquinas dos peíños ao centro dos peíños, asi por todo o corpo?.

Tía Juanita: Botas así unha pouca auga no medio do lombiño e vas das esquinas para dentro hasta aqui a nouquiña, sempre para arriba. Eu: E cando chegas a nouquiña, volves outra vez ós peiños?.

Tía Juanita: Outra vez, e vas contando as veces que o fas.

Francisco: Porque á túa irmá foronlle ali sacar o aire e dixo, estas non son horas, hai que vir co sol. 
Tía Juanita: Si agora che chegan a ti de noite para llo sacar non llo sacas, que chegue a súa hora, ou polas doce, ou á media tarde sempre que faga sol.

Eu: ¿E sempre vai desde as esquinas ó centro?.

Tía Juanita: Ti empezas nas puntas dos dediños dos pés, e vas indo, vas mollando, e zas, zas, os brazos non, só polas perniñas por a parte de atrás, polas cachiñas...ca auga choquiña.

Eu: Unha vez pasadas as nove veces ¿que se fai?.

Tía Juanita: Nada, pós o miniño limpo con roupa e despois vas atender a borralla que está correita, que foste limpando con el, con esa cóase por un trapo limpo, ó que acabe de baixar a auga ca borralla, queda duriña, asi tapada ó que vexas que queda así o boliño feito abres e fixaste ti nos pelos que son dun xeito ou outro, os que están así espichados tesos, e despois os miúdiños de todo poden ser de conexo ou de gato...xa ves os pelos que ai, branquiños e miúdos, xa son de animais, gordos..xa é doutra maneira, son de xente. Despois colles a auga e tírala, tiras a borralla ó lume...»

Ibid:18-19

Esta exposición de tía Juanita de Montemuiño nos muestra la doble vertiente ritual: la diagnóstica, en la que se detecta «la clasificación del aire», y el elemento curativo ya que la enfermedad «sale» a la bola de borralla.

1. El ritual de quitar o aire en la casa solamente se puede realizar durante las horas del día. Una vez que se pone el sol ya no se puede hacer.

2. La criatura se coloca en posición de decúbito prono, desnuda, sobre una toalla encima de las piernas de la sanadora.

3. Se comienza aplicando el agua con la «borralla» desde los pies, partiendo de sus extremos al centro y se va subiendo por las piernas y la espalda hasta la nuca. Y ahí se termina. No se pasa por los brazos.

4. El agua con la borralla templada va cayendo a una palangana, mientras la sanadora va removiendo el agua de la olla con un «carozo» de maiz.

5. Realizar nueve veces el procedimiento. 
6. A continuación, se viste a la criatura y se procede a colar el agua con la borralla que ha pasado por su cuerpo. De este modo obtenemos una bola de borralla, que hay que abrir. En ella comprobaremos: si el aire se lo ha echado un animal encontraremos pelos de animal. Si ha sido una mujer, los pelos de la mujer. El aire de la criatura ya ha pasado en este caso de su cuerpo a la bola de borralla. Sin embargo, si el aire fuera de difunto no pasa a la bola de borralla, sino que ella misma nos indicará que es de difunto por unos bultos que aparecen en lugar de pelos. Y en este caso habrá que acudir al cementerio para que sea el propio difunto quien saque el aire.

7. Esa bola se quema en el fuego y el agua se tira. El fuego es el elemento purificador que hace desaparecer definitivamente la enfermedad, que en este caso ha quedado en la bola de borralla.

Tanto el número tres como el número nueve son importantes en los procedimientos curativos. Estos números constituyen la delimitación tanto del procedimiento ritual como de la invocación del mismo.

En este ritual se da la doble vertiente: la exotérica, que es todo el proceso ritual exterior y la esotérica, que consiste en la invocación de las palabras durante el mismo, y que no son audibles.

- No es la generalidad, pero también hay casos de quitar «o aire» a personas mayores:

Recogido en el mismo documento etnográfico que vengo citando:

Francisco: Miña sogra recórdase de sacarlle o aire a un de vintedous anos,

E dille ela: Teño vergonza meu fillo.

E dille el: Tamén a teño eu. Eu non teño vergonza ningunha, usted aqui está en plan médico.

Eu: ¿A persoas maiores tamén llo sacades?.

Tía Juanita: Sí, tendo.

Ibid: $19-20$

Para que una persona mayor «coja el aire», tiene que estar enferma. Por ello, los enfermos, cuando pasa un entierro, también tienen que le- 
vantarse de la cama, ya que están expuestos a «coger el aire» de difunto. Pero, además de difunto, también lo puede coger de mujer o animal.

\subsection{Completar el ritual en el cruceiro}

Se confiere una sacralidad al cruceiro $^{4}$ que se manifiesta, al igual que en los templos, a dos niveles:

Sacralidad Permanente, que es el espacio en sí mismo, con toda la simbología que le rodea y

Sacralidad Específica, que es la transformación del mismo espacio mediante una acción ritual.

El autor Xesús TABOADA CHIVITE, en su libro Ritos y Creencias gallegas 1982, realiza un extenso estudio sobre los cruceiros, que a continuación paso a señalar.

La naturaleza mágica y brujeril de las encrucijadas pervive en las creencias actuales. La encrucijada es lugar apropiado para curar muchas enfermedades a base del recitado de un ensalmo o de la realización de determinados ritos.

TABOADA CHIVITE, Xesús (1982): 294-295

En dicho espacio van a ser los propios informantes quienes nos muestren sus vivencias, así como el cambio que se opera a partir de la década de los años sesenta.

La informante, Rosa, quitó «o aire atado» a su hijo y tuvo que ir al cruceiro a las doce de la noche. No he recogido ningún relato en el que se acuda al cruceiro para «desatar ao miniño», a las doce del mediodía.

En el cruceiro existen toda una serie de rituales. Voy a referirme a continuación al propio testimonio de la informante, Rosa, de sesenta años, que pertenece a la parroquia de Olveira. Recogido en el documento ACasa d'Agra 1999.07.21,3-10:07.

${ }^{4}$ CRUCEIRO: (Según el diccionario Normativo Castelán-Galego 1988).- Cruz de piedra colocada sobre un basamento en las encrucijadas o cerca de una iglesia.

«CUADERNOS DE ESTUDIOS GALLEGOS», Tomo L, Fascículo 116, Santiago 2003. 
Rosa: $O$ aire sácano (na casa) e se ademais está atado hai que ir a unha encrucillada ás doce da noite. E a primeira persoa que pasa andando.

Eu: ¿Home ou muller?.

Rosa: Home ou muller, sempre que non sexa animal, si é un can ou un gato, xa tes que ir outra noite, ten que pasar un cristián, entón esperas ali co meniño, e dis: ¿que se lles fai ós presos?.

Contestan: "Os presos céibanse»

Coro: $E$ córtanche o cordón.

Rosa: As manciñas ou os peínos, e xa queda ceibo.

Tía Dolores: A que está na cama (a súa filla mais vella tolleitiña), tamén llo tiramos.

Rosa: E mais a José Antonio, tía Flora de Montemuiño, si home, e ademais desmarrámolo ali no cruzamento.»

GALIZA INFORMANTES 1999: 1-2

El testimonio que acabo de exponer, nos indica el reforzamiento del ritual de quitar o aire en el cruceiro a causa de que no es suficiente el ritual realizado en la casa, ya que el niño además de «tener el aire» está «atado».

1. Se le atan al niño los pies y las manos con una cuerda.

2. Se espera a la primera persona que pase delante de ellos.

3. Si en lugar de una persona pasa un animal, ya no se puede seguir adelante con el ritual.

4. A la primera persona que pasa se le dice: «Que se lle fai a un preso»5.

5. Tiene que responder: Séivase ${ }^{6}$.

6. La mujer, que está con la criatura en sus brazos, entregará unas tijeras a esa persona y le dirá: Libérame a este miniño ${ }^{7}$.

7. Cortan las cuerdas y el niño queda liberado del aire al que estaba atado.

\footnotetext{
${ }^{5}$ Traducción: qué se le hace a un preso.

${ }^{6}$ SÉIVASE: se le suelta (expresión la aldea de Bretal).

${ }^{7}$ Traducción: Libera a este niño.
} 
La hermana de Rosa, que está en la cama, tiene unos sesenta y un años. A ella le sacaron el aire y José Antonio, su hijo, tiene unos treinta años en el momento de realizar esta investigación. El ritual transcurre en la década de los años setenta. Indico las edades para situar en el tiempo las acciones del mismo.

Con relación al ritual en el cruceiro, Xesús TABOADE CHIVITE, en su libro arriba mencionado, señala:

Sin embargo, el fondo mágico del ritual, como he dicho en otro lugar, se advierte, aparte de su valor apantomántico, en el simbolismo que entraña las cuerdas con que atan al niño y las trabas que constriñen su desarrollo normal: función simpatética en que la rotura de aquellas produce la de éstas.

TABOADE CHIVITE, Xesús (1982): 295

La función simpatética es el elemento explicativo analítico del autor, la cual equivale a mi análisis de la transposición del signo al símbolo mediante la acción simbólica, partiendo siempre de que en el signo está la enfermedad. El símbolo, en este caso, tepresenta las cuerdas que le constriñen. Y mediante este símbolo y la acción simbólica correspondiente, en la que se encuentra todo el ritual, se produce la resolución de la situación.

El Cruceiro es muy importante en toda la cosmovisión gallega. Sin embargo, a todos no se les confiere actualmente el mismo cometido. En la parroquia de Olveira, van a ser el Cruceiro de la Virgen del Vixo, así como el de Espiñeirido, los dos únicos que tienen un peto (receptáculo) y en los que actualmente se realizan ofrendas.

En el momento de esta investigación, ya no me es narrado el caso de «ir a desatar» un niño a un cruceiro. Es algo que todavía estaba en vigor en la década de los años setenta. Entonces utilizaban el cruceiro más cercano a la casa, y no era necesario que tuviera un peto de ánimas.

En la parroquia de Olveira, desde que el sacerdote don Francisco Rey comienza a ejercer su magisterio en el año 1962, se dejan de realizar los responsos en las encrucijadas y cruceiros durante la conducción de un difunto. A este respecto, los informantes añaden que la afluencia de los coches constituye un factor añadido. «Despois cos coches acabouse todo ${ }^{8}$ ",

\footnotetext{
${ }^{8}$ Traducción: Todo se terminó con los coches.
} 
reflexionan Angelita de Pérez, de sesenta y siete años y, Francisco Pego, de ochenta y tres. Ambos están recogidos en el documento etnográfico Pablo-Enea 1999.08.08,7-18:27.

Francisco: ...Antes nas encrucilladas parábanse cos mortos e rezábase e botaban un responso un padrenuestro.

Angelita: Despois cos coches acabouse todo.

Francisco:É que é moito traballo para o cura. O de San Pedro botando o responso e o sacristán pasando asi para que lle botaran os cartos, cando non habia mais cartos non había máis responsos. Pero agora que va.

GALIZA INFORMANTES 1999: 11-12

Las narrativas están llenas de picaresca, de variada significación, en todo este asunto, como la de ir echando monedas de poco valor, pero que hacían ruido, para que el cura fuera diciendo más responsos por el difunto en todas las encrucijadas del recorrido fúnebre, desde la casa hasta la iglesia. De este modo se iban ganando indulgencias para el difunto y se le ayudaba en su recorrido hacia el más allá.

Estamos ante los últimos relatos que hablan de completar el rito de «sacar o aire» en los cruceiros. Y yo apunto como un hecho muy importante el cambio físico que se opera en estos espacios con el tránsito de los automóviles y la aparición del alumbrado y, así mismo, la negativa de los clérigos, ya desde la década de los sesenta a realizar los responsos en dichos lugares. Señalo estos elementos que contribuyen a la desacralización de los cruceiros, no obstante los propios actores sociales actualmente nos pueden mostrar matices de diálogo en los mismos.

\subsubsection{En la parroquia de Olveira-Bretal-tía Angelita de Alboreda}

Tía Angelita de Alboreda, que tenía 89 años en 1998, actualmente vive sola en su casa, si bien su hija acude todos los días a verla, lo mismo que su nuera y demás vecinos cercanos. Ella está muy activa y todavía planta sus verduras y patatas y acude a las romerías. Es todo un personaje en Bretal, es vidente, ya que ve la Santa compañ $a^{9}$, y cuenta sus experien-

\footnotetext{
${ }^{9}$ Santa compaña: (según el Diccionario normativo galego-castelán 1988).- procesión nocturna de las ánimas.
}

«CUADERNOS DE ESTUDIOS GALLEGOS», Tomo L, Fascículo 116, Santiago 2003. 
cias a sus vecinos. A mí me narrará sus experiencias porque voy con mi madre. Ella «saca o aire», si bien en casos excepcionales. Pero el hecho está ahí, del mismo modo que con tía Juanita de Montemuiño: «ei de sacarllo un día destes a unha miniña da Puebla ${ }^{10} »$. Sus relatos biográficos están recogidos el 7.07.1998,2:

- Tía Angelita saca «o aire», pero en lugar de hacerlo «de pies a nuca» lo hace «de nuca a pies»

Recogido en el mismo documento arriba indicado.

Tía Angelita: Eu sempre lavei para abaixo, xa teño oído que ela lava para arriba, pero con, e cómo é eso, vaille para a cabeza, para abaixo foi toda a vida. As de Cristino e Manuela lavaban para abaixo, pero non lavaban para arriba. Non é para riba, para arriba bótalle logo para a cabeza, para baixo sae pa fóra.

Miña nai: ¡Ah!, sae para fóra.

Tía Angelita: E visto con.

Ego: .... ¿E cantas veces hai que pasar a borralla?.

Tía Angelita: Nove veces.

Ego: ¿Hai que decir algunha oración?.

Tía Angelita: E despois si queres vas a San Migueliño.

Miña nai: ;Ai si!, tamén fomos nós, tes que pasar por debaixo do santo. Tía Angelita: Nove veces debaixo da mesa (fai o gesto coa súa mesilla de noite, estando dúas personas e di): dame o miniño, ten o miniño, eu collo por aquí e ela cólleo por aí (dandolle a volta a unha pata da mesa de noite), así nove veces dicindo: «SAN MIGUELIÑO, QUÍTALLE O AIRE A ESTE MENIÑO».

GALIZA INFORMANTES 1998: 8

En este relato y respecto a sacar el aire surgen más casas en Bretal que ya lo hacían. Si bien el procedimiento y la técnica son los mismos, existe una variante que tía Angelita considera de gran importancia y que consiste en el hecho de que al ir de los pies a la nuca, el aire, para tía Angelita, se va para la cabeza y, al contrario, el aire sale por los pies. Tía Angelita

${ }^{10}$ Traducción: Uno de estos días se lo sacaré (el aire) a una niña de la Puebla.

«CUADERNOS DE ESTUDIOS GALLEGOS», Tomo L, Fascículo 116, Santiago 2003. 
lo completa con San Miguel, pasando a la criatura debajo del santo y repitiendo otra vez la acción el mismo número de veces, es decir, nueve veces, invocando a San Miguel para que saque el aire al niño. En el caso de Tía Angelita es ella la que hace la simbiosis entre sus conocimientos curativos y la religiosidad popular. Con San Miguel volverá a establecer el numero nueve, junto con la rogativa.

Estamos en la misma aldea y con variantes en los rituales. A este respecto, Mary DOUGLAS, en su libro Símbolos naturales Exploraciones en cosmología 1988, (título original Natural Symbols - Exploration in Cosmology, 1970), afirma:

Es imposible la existencia de un esquema de símbolos interculturales. Primero, porque todo sistema simbólico se desarrolla de forma autónoma y de acuerdo con sus propias normas; segundo, porque los condicionamientos culturales ahondan las diferencias entre ellos, $y$ tercero, porque las estructuras sociales añaden un elemento más de diversificación.

DOUGLAS Mary (1988): 13

Para la autora, es imposible un esquema de símbolos interculturales. Añado, además, que incluso dentro de una misma cultura y ante una acción simbólica que persigue un mismo fin, las variantes en sus esquemas simbólicos son múltiples. En ellos se dan manifestaciones que conservan ciertos elementos de la estructura simbólica, como puede ser pasar nueve veces el agua con la borralla por encima de la criatura, junto con las palabras correspondientes. Pero también se puede dar, en un mismo contexto cultural, una acción simbólica con un único elemento estructurante, tal y como expongo a continuación.

Así, encontramos ante la situación de «quitar o aire do miniño» una acción simbólica realizada en la aldea de Goyanes, Boiro, (Coruña), en la cual solo se da un único elemento estructurante de la misma, el número nueve, ya que van a ser nueve los días que cierren el ritual.

\subsubsection{En Goyanes, Boiro -Coruña- «quitar o aire aos miniños» envueltos «na folla do aire» \\ Pertenece a los relatos biográficos de Tía Manuela a Tata Pablo-Enea 1999.10.06,3-13:38. Aclaracions de tía Manuela a Tata:}

«CUADERNOS DE ESTUDIOS GALLEGOS», Tomo L, Fascículo 116, Santiago 2003. 
Tía Manuela: Era a folla do aire, e durmía o miniño nove días nesa folla, e cando lle quitaban a folla ó pobriño saíalle a pel pegada na folla, nove días sin lavar o miniño.

Eu: ¿Iso facíase na súa aldea?.

Tía Manuela: Sí, que ían buscar a finca da torre.

Eu: ¿Qué era? ¿unha folla moi grande?.

Tía Manuela: Unha folla moi grande.»

GALIZA INFORMANTES 1999: 15

Para tía Manuela, el nombre de la hoja, era «a folla do aire», pero nada más. Era importante el tiempo de exposición ritual: eran nueve días los que había que mantener la hoja en contacto con el cuerpo, para que $o$ aire del niño quedara en la hoja. No se me narra ninguna jaculatoria ni el hecho de ir al cruceiro. Se trata de un recuerdo de infancia de la informante.

A continuación mostraré otro caso en el cual, al igual que en el anterior, se da un único elemento estructurante ritual. En este caso se trata de ir a la encrucijada a las doce de la noche.

\subsubsection{En la Puebla del Caramiñal -Coruña- introducen a los ni- ños en el cajón de los ornamentos litúrgicos}

El niño, en contacto con las ropas sagradas del sacerdote, entra en la primera fase de purificación, que será completada en el cruceiro a las doce de la noche. Seguimos en la transposición binaria del paso de una situación fisiológica impura en la que «ten o aire» a una situación fisiológica pura de resolución de la enfermedad.

En la Puebla del Caramiñal, población situada a unos quince kilómetros de mis parroquias de estudio, las madres, con objeto de «sacar o aire» de los niños, los depositaban, con el permiso del sacristán, en el cajón de los ornamentos litúrgicos para que, de este modo, ante el contacto con lo puro, lo sagrado, el aire de los niños, impuro, entrara en la primera fase de translación del ritual, culminándolo en el cruceiro a las doce de la noche. Esta realidad me es dada a conocer en los relatos biográficos de tía Manuela a Tata.

Recogido en el documento A- Pablo-Enea 1999.09.26,7.

A Tata: Rebolábanos alí.

Eu: ¿O cura deixaba facer eso?.

«CUADERNOS DE ESTUDIOS GALlEGOS», Tomo L, Fascículo 116, Santiago 2003. 
A Tata: Non sei, o cura non estaría a iso, era o sacristán, dabasllo ó sacristán.

Eu: ¿Iso para que era?.

A Tata: Para lle sacar o aire.

Eu: ¿Tamén?.

A Tata: E despois ían ás encrucilladas. Tiñan que ser as doce da noite».

GALIZA INFORMANTES 1999:5-6

Esta acción ritual se cierra en la encrucijada a las doce de la noche y es el único elemento estructurante con relación a «quitar o aire».

\subsection{5. «Quitar o aire» en la parroquia de Corrubedo -Coruña-}

El hecho se desarrolla en la parroquia de Corrubedo. En la de Olveira este ritual no se encuentra a lo largo del siglo veinte, pese al escaso recorrido espacial existente entre ambas parroquias, unos tres kilómetros. Va a ser en la parroquia de Olveira donde se halle toda la elaboración ritual de «quitar o aire» en las personas. En la de Corrubedo, sin embargo, el ritual se realiza en un animal doméstico: el gato.

Pablo-Enea 1999.08.05,4.

Eu: Aqui en Corrubedo non hai ningunha persoa que sacara o aire dos nenos?.

Tía Carmiña: Non, aqui non.

Eu: ¿Nin na lareira co loureiro?.

Tía Carmiña: Si, co laureiro ás gatas cando parian para que non lles dera o aire ós meniños, porque antes non se tendía a roupa en tendais, antes tendiase a roupa polos muros.

Eu: Xa me acordo cando eu era pequena.

Tía Carmiña: E cando paría unha gata, as mesmas da casa queimaban o loureiro e pasaban a gata tres veces para lle quitar o aire. Queimaban, facian unha fogueira na lareira cos loureiros e despois collian a gata e facian: unha dúas e tres, en círculo, e xa a gata quedaba sin o aire....iso era cando era das gatas, agora xa é outra cousa que ademais xa se plancha».

GALIZA INFORMANTES 1999: 24

En este texto se manifiesta el proceso ritual sobre la gata para que no contamine con sus fluidos.

«CUADERNOS DE ESTUdIOS GALLEGOS», Tomo L, Fascículo 116, Santiago 2003. 
1. Purificación del animal para que no contamine con su aire al niño o personas enfermas.

2. La purificación del animal se realiza con el humo del laurel.

3. Utilizando el símbolo del círculo y el número tres. Es decir, haciendo girar en círculo al animal durante tres veces encima del humo.

4. El animal tiene que ser hembra, en este caso es una gata, que bien estuviera recién parida o en celo. Tras este ritual la gata ya queda purificada, su «aire» deja de ser contaminante y de producir la enfermedad.

5. La contaminación a través del aire se produce por el hecho de pasar, bien por encima de la ropa que está tendida, bien por encima del niño o persona enferma.

6. La informante afirma que una vez que se introducía la plancha, ésta, con el calor, también purificaba la ropa.

Los fluidos de la gata son transgresores, ya que producen la enfermedad en los niños, al dejarles «el aire» de dichos fluidos. El fluido es, por lo tanto, un signo. Dicho signo va a ser purificado mediante una acción simbólica en la que se utilizan una serie de símbolos que, en este caso, van a ser los siguientes: el humo del laurel y la realización de tres círculos con el cuerpo del animal. El número tres es el que realiza el cierre del ritual, pero para ello, el animal tiene que estar inmerso en los símbolos, para que se produzca su transformación, es decir, que su «aire» deje de ser contaminante, impuro y potencial transgresor es decir causante de una enfermedad. El animal pasa a ser puro, realizado ya el ritual. Sus fluidos ya no producen enfermedades.

\section{2.- «LEVANTAR A PALETILLA»}

Antes de comenzar a desarrollar este ritual, voy a nombrar al autor MARIÑO FERRO, Xosé Ramón, en su obra Medicina Popular II (1986) ya que tiene un extenso trabajo realizado respecto al mismo.

En Golda (Pontevedra) se atribuye la causa de la enfermedad a la caída de tres bultos «desde la articulación del codo hasta la de la muñeca». En algunas zonas de Ourense se habla, en general, de cuerpo caído. En Porto do Son (Coruña) el curandero recita este ensalmo: 
"Levanta paletilla o espinilla, a

F.de T.,

Corazones o riñones,

Juntas y conjunturas,

Cada hueso a su lugar,

El cura a la misa en el altar,

Tres palomitas en el palomar,

Por encima de las olas del mar.

Con el poder de Dios...»
«Levanta paletilla o espinilla, a F. de T.,

corazones o riñones, xuntas e conxuntas, cada oso ao seu lugar, o crego á misa no altar, tres palomiñas en el palomar, Por encima das olas do mar. Con el poder de Dios...»

Como la enfermedad consiste en el desplazamiento o caída de huesos y vísceras, engendra un desequilibrio en el cuerpo.»

MARIÑO FERRO, Xose Manuel (1986):101

El autor ofrece una definición sobre qué es la enfermedad. Además, muestra las palabras que llevan a la curación de la misma. Dichas palabras, en el contexto estudiado por mi, (en este caso en la parroquia de Olveira) pertenecen al ámbito esotérico. Solo pueden ser transmitidas oralmente y no se deben escribir, para que de este modo no pierdan «la virtud». No obstante, tengo el testimonio directo del antropólogo Don Xosé Manuel González Reboredo quien me refiere que en el trabajo de investigación también existe otra actitud diferente del informante que posee un ritual esotérico. El autor me lo testimonia del siguiente modo: «Mantiene el esoterismo de dicho ritual con la persona que acude a su curación, sin embargo, para el «extraño», en este caso el etnógrafo, le transmite las palabras previamente asentando el principio de confianza»».

En mi posicionamiento científico me baso en el principio de realizar el análisis partiendo tanto de la simbolización como de la significación que los propios autores sociales confieren a las acciones rituales que a continuación sigo exponiendo.

La acción de levantar a paletilla, puede ser realizada tanto por hombres como por mujeres. De hecho, tía Juanita de Montemuiño se la transmitió a uno de sus hijos.

\subsubsection{Qué es tener «a paletilla no chan»}

Las explicaciones son muy variadas, sobre todo entre la gente de la aldea y pueden oscilar desde decir que se les ha caído un hueso, hasta decir que se trata de una depresión. 
La propia tía Juanita de Montemuiño dirá que es una situación de «perder o solaz», es decir, que físicamente no ocurre nada aparente. Sin embargo la persona se encuentra muy cansada, con ganas de estar acostada.

A continuación va a ser una informante quien narre cómo entiende ella ese «ter a paletilla no chan» en el mismo documento arriba indicado. Rosa, de sesenta años, de la parroquia de Olveira, lo expone en el documento Casa d'Agra 1999.07.21,3-10:07.

Eu: ¿A paletilla é un óso?.

Rosa: Disque non, a min dixéronme tía Manuela de Arriba, a paletilla é isto que fas así (bota a man ó peito e fai o xesto de canseira), e así como cha levantan, xa quedades, xa quediei san, iso é a paletilla que se aquela, é a canseira que tés ti no corpo. Pode ser por calquera cousa, de traballo, é un pesar que ti poidas coller, unha depresión e xa che baixou a paletilla, quedas asi sin moral, quedas así.

GALIZA INFORMANTES 1999: 4

Para esta informante el hecho de «ter a paletilla no chan» está relacionado tanto a un exceso de trabajo y cansancio, como a una depresión. Ambas variables son válidas.

1.2.2. Comprobación de que la persona tiene «a paletilla no chan»

La comprobación de que la persona tiene «a paletilla no chan» la he visto realizar a tía Encarnación de Montemuiño en Olveira, (hermana de tía Juanita de Montemuiño), y yo he fotografiado todos los pasos. Esta técnica yo la he aprendido y he grabado sus pasos en fotografías, que aquí no las expongo a causa de la extensión de este artículo.

1. En primer lugar, la curandera mira a la persona y le tiene que «dar a alma», es decir que intuitivamente puede proceder «levantar la paletilla».

2. Se cogen ambos brazos de la persona sentada en el suelo. Se elevan hacia arriba y se comprueba que los dedos índices están parejos. Cuando uno está más arriba que otro, significa que la paletilla está caída.

\subsubsection{Levantar «a paletilla» con la persona presente}

Este punto es continuación del anterior. 
1. La persona se sienta en el suelo con las piernas juntas.

2. Se coloca detrás de ella la persona que realiza la técnica.

3. Coge los brazos de la persona y los extiende en cruz, haciendo un movimiento hacia arriba y hacia abajo tres veces.

4. Coloca ambas manos, una encima de otra, encima de su propia cabeza.

5. Hay que dar tres golpes en la cabeza diciendo la frase que se ha transmitido.

Tía Juanita y tía Encarnación ambas pertenecientes a la casa de Montemuiño y son hermanas, me han advertido que si no se saben «as palabras», aunque se realice la técnica correctamente, ésta no sirve para nada. Es decir, cualquier persona puede aprender a hacerlo incluso viéndolo hacer, pero sin las palabras no tiene efecto.

Al igual que para constatar que la paletilla èstaba caída se hizo el ejercicio de elevar ambos brazos y juntar los dos dedos índices, del mismo modo se realiza la comprobación del remedio y si se ha levantado la paletilla, ambos dedos índices tienen que estar a la par. En caso de que no lo estén, esto significaría que no se ha solucionado el problema y hay que volver a repetir todo el proceso.

\subsubsection{Levantar «a paletilla» a distancia}

En este caso de curación a distancia es imprescindible nombrar a la persona que necesita que se le levante la paletilla.

1. Se nombra a la persona. Es importante decir el nombre y los dos apellidos.

2. A continuación se dicen las palabras rituales.

3. Esta acción hay que realizarla tres veces.

Sabes si la persona se ha curado porque así lo comunican posteriormente.

A continuación voy a escribir lo que me fue narrado por tia Juanita de Montemuiño. Recogido en el documento etnográfico Casa d'Agra 1999.07.23,5-11:53, correspondiente a la transcripción realizada el 21 de xullo de 1999. A las 13:00. 
Tía Juanita: Cando non teño a persoa (diante); menos de tres veces no deixo de decir (as palabras).

Eu: Repite o rezo co nome, e alá ó lonxe à persoa levántaselle a paletilla.

Tía Juanita: Si con, que nome o nome de ela, e mais o que hai que decir, e sanda pobriña.

A Nora: A miña nai tamén lla levantou à miña sogra desde aquí».

GALIZA INFORMANTES 1999:26

La palabra también tiene poder a distancia, confluyendo dos elementos muy importantes: el hecho de nombrar a la persona a la que va dirigida la oración y el decir la oración correspondiente. Estamos ante una acción ritual que corresponde al simbolismo figurado por excelencia, ya que la persona a la que hay que curar no está físicamente con la sanadora.

\section{3.- CURAR «AS BELOÍNAS»}

Este ritual curativo lo tengo recogido tanto en la parroquia de Olveiera, Bretal, como en la de Boiro, Goyanes. En ambos contextos las palabras que son nombradas corresponden al ámbito exotérico, tal y como se refleja en el relato biográfico de tía Manuela a Tata ${ }^{11}$, correspondiente a la aldea de Goyanes, Boiro. Recogido en el documento etnográfico PabloEnea 1999.10.06,3-10:00-12:30, trasncripción de la grabación 1999.10.06,3-13:38.

\subsubsection{En Boiro, parroquia de Goyanes}

Tía Manuela: Colles un vaso à metade de auga, colles nove grans de trigo, neses grans do trigo vas ò ollo e dis:

A LA GLORIOSA SANTA LUCÍA, TRES AGUJAS DE ORO TENÍA CON UNA COSÍA CON OTRA BORDABA CON OTRA QUITABA LAS BELOÍNÃS A QUIEN LAS TENÍA. PADRENUESTRO Y AVE MARÍA A LA GLORIOSA SANTA LUCÍA. NOVE VECES.

\footnotetext{
${ }^{11}$ Tía Manuela define a beloiña como un bultiño, como si fuera un grano de trigo que sale entre la pupila del ojo y el cristalino.
}

«CUADERNOS DE ESTUDIOS GALLEGOS», Tomo L, Fascículo 116, Santiago 2003. 
Quitabas o gran e o botábalo no vaso de auga, así esta xaculatoria con cada gran; a la gloriosa santa Lucía, tres agujas de oro tenía con una cosía con otra bordaba con otra quitaba las beloiñas de los ojos a quien las tenía un padre nuestro y un ave maría a la gloriosa santa Lucía.

Facendo a sinal da cruz cada vez no ollo, desde a cella así con nove grans e nove días. Ó botar o gran na auga verás que ten a beloiña aqui arriba no gran.

Eu: Ó seguinte día falo con outra auga e outros grans e despois iso tirase.

Tía Manuela: Cada día tíralo e auga fresca e grans novos, así nove dias e os nove dias desaparece, non sei si era a fe ou era o que era, desaparecía e xa non andaban nin en médicos nin en nada.

GALIZA INFORMANTES 1999: 15

En esta exposición ritual se halla el procedimiento del mismo, así como el elemento de la creencia tal y como la misma informante le dota de significado.

1. En este relato existen unas palabras, la «jaculatoria», que dice tía Manuela a Tata. Pero a diferencia de las palabras de sacar $o$ aire o levantar a paletilla, éstas pertenecen al ámbito público, exotérico, se dicen en voz alta y su poder no radica en las cualidades especiales que se confieren tanto a la persona portadora de la jaculatoria como a la jaculatoria en sí, sino en toda la acción ritual.

2. En la jaculatoria está Santa Lucía, patrona de las costureras, de ahí su mención de las agujas en la jaculatoria, confiriéndole a una de ellas el poder de quitar las beloiñas.

3. Formular la jaculatoria durante un periodo de tiempo ritual que se cierra en nueve días y nueve veces cada día.

4. Realizar, además, la señal de la cruz con el grano de trigo encima del ojo, sin tocarlo.

5. La enfermedad pasa al grano de trigo. En él es donde se queda la beloiña. Estamos ante un denominador común en todos los ritos de curación gallega: la enfermedad queda fuera del cuerpo, en otro objeto, pasando de este modo del signo al símbolo. 
6. Tía Manuela reflexiona diciendo que no necesitaba ir al médico y no sabe qué producía la curación: «la fe o era o que era». En su biografía son de señalar estos dos importantes aspectos: primero, su infancia y primera juventud transcurren en su casa con un bisabuelo curandero, donde la palabra y la fe curaban a muchas personas, y en segundo lugar pasará luego a vivir bajo la influencia de la tecnología médica actual.

En tía Manuela se dan esas dos formas de relacionarse las personas con el propio cuerpo enfermo:

1. A nivel de tradición. Utilizando el poder de la palabra y la fe, se «invita» a la enfermedad a que abandone el cuerpo, que salga fuera.

2. A nivel empírico. Se aborda la enfermedad tratándola desde el mismo cuerpo enfermo.

\subsubsection{En Olveira, parroquia de Bretal}

La distancia geográfica entre Boiro y la parroquia de Olveira es de aproximadamente unos treinta kilómetros y, sin embargo, para la misma enfermedad ocular va a variar la técnica de realización del rito de un lugar a otro.

Francisco Pego ${ }^{12}$, de Bretal, tiene ochenta y tres años en el momento de recoger sus relatos biográficos. En su infancia recuerda haber visto a su abuela sacar beloiñas y él mismo narra la técnica que ella utilizaba. Recogido en el documento Casa d'Agra 1999.07.20,2-17:20

Franciso: Eu non sei, antes se botábase na vista como a cabeza dun alfinete que se chamaban beloiñas. Corría o ollo miña avoa, Asunción do Río. E decía as palabras chorando, decíaas de corazón con sentimento, parece que estouna oindo.

Eu: $E$ as decía en voz alta.

Francisco: Decía: SANTA LUCÍA, TRES AGUJAS DE ORO TENÍA, CON UNA BORDABA, CON OTRA COSÍA, CON OTRA QUITABA LAS BELOIÑAS.

${ }^{12}$ Francisco Pego define las beloiñas como un quistiño pequeño. 
E decia tres veces correndo con unha agulla por enriba do ollo. E aquela persoa desapareceulle...pero tiña aquela cousa pedindo.

Angelita: E saíalle do corazón».

GALIZA INFORMANTES 1999: 5-6

A diferencia del relato anterior el informante narra el ritual de «quitar as beloiñas», tal y como lo conserva él en su memoria, puesto que ha visto la vivencia de su abuela realizándolo, sin embargo tía Manuela a Tata, en su testimonio es ella quien ha sacado beloiñas.

1. En este texto la oración que se dice es igual a la que dicen en la zona de tía Manuela a Tata, en Boiro. También es igual el hecho de decirlo en voz alta.

2. En Boiro se cierra el ritual en el número nueve. En la parroquia de Olveira en el número tres.

3. En Boiro se pasa el grano de trigo haciendo la señal de la cruz encima del ojo, sin tocarlo.

La Curación de la beloiña me será ampliada al día siguiente, tal y como se recoge en el documento Continuación da transcripción realizada o miércoles día 21 de xullo de 1999.

4. Cada vez que se va a pasar la aguja por encima del ojo hay que introducirla previamente en agua bendita, para reforzar de este modo sus propiedades curativas.

5. En la parroquia de Olveira la aguja es de oro y con ella se toca el cristalino del ojo.

Con los elementos simbólicos señalados, es decir, el material noble del oro, y el agua bendita, se realiza la acción curativa uniendo ambos elementos a la acción de la palabra. De este modo la enfermedad sale del signo al símbolo.

«CUADERNOS DE ESTUDIOS GALLEGOS», Tomo L, Fascículo 116, Santiago 2003. 


\section{TRANSPOSICIÓN BINARIA DEL SIGNO AL SÍMBOLO SIN LA ACCIÓN DE LA PALABRA}

2.1. CASO A: SÍMBOLO EXTERNO. «Pau de abeneiro ${ }^{13}{ } »$

En los relatos biográficos de tia Manuela a Tata se encuentra una forma de curación en la que el mal es depositado en un objeto cuya evolución condiciona la curación de dicho mal. Esto se da en la romería de San Benitiño en Serans (Coruña). Al pasar el pañuelo con el aceite por la zona donde se encuentra la enfermedad. Más tarde, este pañuelo es depositado en un lugar sagrado: el muro de la ermita o la fuente de la misma.

En este caso el objeto también es colocado en un lugar sagrado, dentro del hogar gallego: la lareira. En ella, además de las actividades culinarias, también se hacen unos preparados especiales para elaborar la borralla de quitar o aire. En la lareira se quema el laurel para que con su humo se le quite o aire al animal. También en ella se cuelgan dos trozos de abeneiro para que, al secarse éste, desaparezca la enfermedad.

Sigo en todo esto las propias palabras de tía Manuela a Tata, que tiene sesenta y ocho años. La curación transcurre en la infancia de ésta última que transcurre en la década de los años treinta.

Relato recogido en el documento A-Pablo-Enea 1999.09.26,7-10:33.

A Tata: E as lombrigas, eu tamén as tiven jeh!, ia para a escola e o cu a picar a picar, eu a rascar e turraba dela e era unha lombriga.

Eu: ¿E que vos daban?.

A Tata: Uns paus dos abeneiros, non sabes ¿o abeneiro?, por maio botan unha flor moi bonita branca, os paos amarrábanos asi e púñanos na gramalleira. Eran as cociñas de lareira e na cociña de lareira había unha cadea colgada ali enriba, era para colgar os potes, colgában os alí, e nesa cadea poñian os paos eses e o secar secaban as lombrigas.

GALIZA INFORMANTES 1999: 6

${ }^{13}$ ABENEIRO: (según el diccionario normativo galego-castelán 1988).- Alnus glutinosa, aliso, árbol betuláceo de tronco grueso, copa redonda y hojas viscosas. Abunda en las orillas de los ríos.

«CUADERNOS DE ESTUDIOS GALLEGOS», Tomo L, Fascículo 116, Santiago 2003. 
El hecho afecta a la propia informante y, en efecto, así es como ella se cura del problema de los parásitos intestinales. No toma ninguna medicación específica, ni por vía oral ni rectal, pero es conocedora de la acción ritual que se está realizando para su curación. Esta consiste en que la rama de abeneiro colgada encima de la lareira tiene que ir secándose. En la medida que esa rama, que representa a las lombrices, va perdiendo su frescura, las lombrices van desapareciendo poco a poco de su cuerpo. Y, en efecto, así ocurre con esta niña. Estamos ante la proyección externa a nivel físico de una enfermedad. Somos hijos de toda esta tradición, que en este fin de siglo, en el que la tecnología médica es cada vez más elaborada, vemos que va desapareciendo rápidamente.

Ya solo nos queda firmar actas de defunción respecto a estos tradicionales procesos curativos. No obstante en estos últimos años estamos presenciando en todo este primer mundo «desarrollado», imbuido de las nuevas tecnologías médicas en los procesos curativos, un fenómeno de vuelta a la creencia en la mente y su poder curativo ilimitado, de ahí que se está dando la multiplicación de los anuncios de cursos de Reiki, Sanación, etc. ¿No estamos volviendo, a nuestra profunda estructura tradicional enumerada en este trabajo?.

\subsection{CASO B- SIMBOLO EXTERNO: CARNE CRUDA}

El caso que narro a continuación es vivido por el informante, que cuenta con unos treinta y cinco años en el momento de realizar este documento. Este caso se enmarca en un contexto intercultural. Recogido en el documento Pitelos 1999.07.14,3-8:06, transcripción de la grabación realizada en la romería de San Benito 1999.07.11,7.

(Poño en marcha a gravadora, está narrando como estando en Cádiz traballando de mariñeiro, tiña unha verruga e mandaronlle coller un anaco de carne con sangre e poñerllo enriba da verruga, e despois que era moi importante que esa carne non a comera nin gato nin can e que a enterraran nun sitio donde non foran estes animais).

«Home: Era importante que non comera a carne nin gato nin can, ben pois ó seguinte día a verruga fush, desapareceu, xa mo dixo él jeh!, mañana ya no la tienes, foi no ano oitenta e dous. Outro día, tiña aquí unha verruga e agarrouse no aparello, tirei por él, e arranqueina, carallo canto sangrou, o costa (patrón do barco) gastou mais dunha botella de iodo.

«CUADERNOS DE ESTUDIOS GALLEGOS», Tomo L, Fascículo 116, Santiago 2003. 
Eu: Perdón, ¿o anaco de carne que tiña sangre púxoo encima da verruga?.

Home: Fas unha cruz así, e dormín co anaco de carne toda a noite. Eu: ¿Pero tapouna?.

Home: Non tapei nada, e cando espertei ó outro día xa non tiña nada, foi un andaluz en Cádiz, era mi jefe, yo estaba haciendo la mili y era mi jefe en el trabajo mío que yo tenía.

Ibid:6

Se bendice la carne que se coloca encima de la verruga, y debido a que es la misma carne la que coge el mal del cuerpo, hay que protegerla y enterrarla. El perro y el gato son dos animales a los que se les confiere la prohibición de comer dicha carne. La verruga desaparece al día siguiente.

\subsection{CASO C- SÍMBOLO EXTERNO AGUA DE AMORTAJAR}

El hecho que narro a continuación se va a realizar en Goyanes, Boiro, con la hermana de tía Manuela a Tata, que está allí presente.

Testimonio recogido en sus relatos biográficos y que transcurre a finales de los años mil novecientos treinta.

Registrado en el documento etnográfico Pablo-Enea 1999.10.06,3$13: 38$

Tía Manuela: Hai un tempo, cando eu era rapaza, pois na miña aldea, que eu son de Boiro pero vivía en Goiáns, e había unha señora que se dedicaba a lavar os defuntos, é cunha toalliña, que antes non habia esponxas, lavaban o defunto cunha auguiña morna, non quente. E miña irmá tiña os lamparóns, e decian os médicos que se abrían. Era unha especie como dun ovo e na primavera abría e votaban un liquido, e non lle daban nada. O médico decía que fixera baños de sol,...despois cerráballe, todo o ano estaba cerrado aquilo, pero ò chegar a primavera abría.

Habia ali unha señora que se dedicaba a lavar os difuntos, e colleu e dixo. Mira, o remedio que hai mellor para iso é lavar iso coa auga que lavan os defuntos, o defunto que sea de vello, non dunha enfermidade mala, e xa verás como iso desaparece, e asi foi, vano lavar, e despois ata lle pasou a man do defunto por encima; isto é unha cousa que se che vai da memoria, xa deixas de pensar que tes ali 
aquilo, e despois cando mirou fóraselle, iso foi tan certo, porque era miña irmá.

Eu: ¿Vostede cantos anos tiña entón?.

Tía Manuela: Doce anos.

GALIZA INFORMANTES 1999: 1-2

El relato corresponde a la infancia de la informante, ella insiste en la veracidad del mismo por dos motivos, lo ha visto realizar y ha presenciado en su propia hermana el proceso curativo del mismo.

1. Estamos ante una persona que acaba de morir. Entra entonces en un primer estadío de Separación, siguiendo la clasificación de Arnol VAN GENNEP, en su obra Les Rites de Passage (1909). En este estadío se confiere al difunto una acción curativa. Sin embargo, en el estadío de Margen, $o$ aire del difunto es «transgresor» y puede producir una enfermendad

2. Entre las características de la persona que acaba de morir es importante que se trate de un anciano y que su muerte no haya sido producida por una enfermedad contagiosa.

3. Los elementos curativos que realizan la función de símbolo, con el consiguiente trasvase al mismo de la enfermedad, van a ser: el agua de amortajar y la mano del difunto.

4. Insiste tía Manuela que cuando la enfermedad sale del cuerpo queda ya olvidada.

5. El siguiente paso es el de reconocer que ha desaparecido la enfermedad.

\subsection{EN LA PARROQUIA DE OLVEIRA, «A PEDRA DA PESOA» SOLUCIONA PICADURAS DE VÍBORA}

Las picaduras de víbora son mortales en caso de no actuar rápidamente. Durante este siglo veinte ha existido un método para que el veneno de la víbora, inoculado mediante mordedura en la persona, no circule ni por el torrente sanguíneo ni linfático y salga al exterior. Voy a exponerlo a continuación. Este hecho se sitúa en Bretal, aldea de la parroquia de Olveira. Recogido en los relatos biográficos de Francisco Pego, de 83 años. Pablo-Enea 1999.08.09,1-13:29. Transcripción cuya grabación es realizada o miércoles 21 de xullo de 1999. Fun as tres e media. 
Francisco: $O$ veneno da culebra atrae a pedra coma o imán atrae o ferro. Esa pedra era a da Pesoa, e non sei si a roubaron pero xa non a temos, estaba na casa de Sieira...é unha pedra que ten o seu misterio como atrae, e despois bendan o pé ca pedra, e cando a pedra desvenda aos nove días, xa a pedra cae na cama.

E méteno para lle sacar o veneno en leite queda todo azul o leite, ese veneno sóltase nun cacharro de leite, hai que darlle ó dono a pedra limpa. Eu seino porque llo vin á miña irmá Benita, e na casa de Sieira tiñan esa pedra, pero despois houvo aqui persoas que as picaron as culebras e tuveron que darlle ós pes, pero haber houvo esa pedra.

Unha vez tío Tan de Suárez, viña con un feixe de lentellas, pisou unha pedra e dixo, iqué fofo está isto!, nunha laxa pisando un regueiro, sacou o pé para ollar, e paf, unha culebra. A do Balón, tamén a mordeu unha culebra, agora esa pedra desapareceu, esa pedra hóuboa, que a puxo miña irmá Juanita que viña da ponte cunha sella de auga, e a víbora estaba así na ponte e ó pisar mordeuna».

GALIZA INFORMANTES 1999: 21

En el testimonio de Francisco Pego, al igual que el anterior de Tía Manuela a Tata, ellos han visto como se realizaban estos procesos curativos y la efectividad de los mismos, desde sus vecinos hasta los miembros de sus propias casas.

1. La piedra, que pertenece a la comunidad y es utilizada por todos sus miembros, desaparece en un momento determinado.

2. El hecho de la desaparición de la piedra es un gesto en el que la responsabilidad de la curación, que es comunitaria, pasa a ser individual. Estos procesos de cambio son los más importantes a lo largo de este siglo XX. La acción comunitaria deja paso al individuo que, en el contexto gallego, se repliega en la casa. Esto ocurre, al igual que con la piedra de la Pessoa, con todo el proceso relacionado con el amortajamiento, en el que era la comunidad la que se responsabilizaba, siendo actualmente la casa individual quien paga a la funeraria.

3. El veneno es atraído por la piedra, con lo cual se le impide que ejerza su efecto sobre la fisiología de la persona. Una vez más estamos ante un hecho de transposición del signo, que es el veneno, al símbolo que es la piedra. En este caso no se produce la enfermedad 
en el signo, sino que «sale» al símbolo sin afectar a la fisiología de la persona.

4. El número nueve en la curación vuelve a aparecer: a los nueve días es cuando ya se suelta la piedra de la herida. Se ha cumplido el ciclo de tiempo establecido culturalmente como curativo.

5. La leche, elemento purificador de la piedra, absorbe el veneno, haciéndolo desaparecer. Desde niña, oía yo los relatos de los mayores en la aldea de Bretal, diciendo que a las culebras les gustaba la leche y por ello iban a los niños, que olían a leche y también iban a las cuadras a mamar las ubres de las vacas.

6. Estos relatos, que forman parte de la memoria colectiva, confieren a la leche propiedades purificativas sobre la piedra. Ésta última ha estado absorbiendo el veneno de la víbora y, a su vez, el veneno se traslada fuera de la piedra a través de la leche, que tan apetitosa es para la víbora.

\subsection{LA GALLINA ES A LA MUJER LO QUE EL GALLO AL HOMBRE}

Comenzaré citando a LEACH, Edmund, en su libro Cultura y comunicación. La lógica de la conexión de los símbolos 1993, (título original: Culture and communication. The logic by wich symbols are connected, primera edición 1976).

El gallo ha sido una metáfora del pene humano en todas las regiones de Europa, al menos desde la Grecia clásica, de manera que las imágenes visuales de la pelea de gallos y de los gallos y las gallinas están muy cargadas de implicación sexual.

LEACH, Edmund: 24-25

A continuación, al igual que indica Leach, voy a exponer cómo el simbolismo de la gallina es a la mujer lo que gallo es al hombre. En el contexto cultural gallego esto ocurre en la curación del postparto. Siguiendo los mismos relatos biográficos de Tía Manuela a Tata, vemos cómo la gallina es indispensable para la curación de la matriz después de cada parto. Y no solamente el caldo de la gallina sino también su carne, a lo que había que añadir el vino de la casa. Pero en caso de no querer tener más hijos, la mujer que acababa de dar a luz tenía que comerse un gallo

«CUADERNOS DE ESTUDIOS GALLEGOS», Tomo L, Fascículo 116, Santiago 2003. 
entero, que es un símbolo de masculinidad y de pérdida de feminidad. Como símbolo de masculinidad, he observado en la romería de San Benito de Serans en junio de 1999 a un grupo de hombres, tocarse unos a otros los genitales durante una subasta de gallos, mientras decían: «ahora o galo». Este gesto esta lleno de significado respecto a los atributos culturales que se le dota al gallo: Su posición jerárquica en el gallinero, un gallo para varias gallinas...por ello tanto en el comportamiento de los hombres en la romería como en el de tía Manuela a Tata respecto a sus partos y cese de los mismos, en ambas situaciones se hallan representadas profundos modelos de comportamientos culturales.

El testimonio de tía Manuela a Tata, de 69 años, está recogido en el documento Pablo-Enea 1999.09.25,6. En él se manifiesta la relación que tiene tanto la gallina como el gallo en la acción fisiológica de la informante.

A Tata: Catro galiñas cada parideiro (risas colectivas de todo el vagón).

Lola: Están oíndo todos.

A Tata: Cada parideiro catro galiñas, unha taza de manteiga con mel, chocolate e mais viño Quinito. Eran as sete semanas de curación que habia que sandar a nai. Porque unha vez díxeronme, jai mira! para non ter máis meniños hai que comer un galo, e comín un galo tamén, era un galo grande».

GALIZA INFORMANTES 1999: 9

El texto tiene las siguientes características:

1. La importancia de la ingestión del caldo de gallina asociado a la curación uterina como importante elemento cicatrizante.

2. El gallo como elemento simbólico masculino asociado a la pérdida de la fecundidad.

\section{CONCLUSIONES}

Los casos de curación aquí expuestos se realizan con símbolos representados, exceptuando el caso de «levantar a paletilla» a distancia, que 
corresponde a un símbolo figurado. En ambos tipos de simbolismo se dan dos grandes situaciones de transposición binaria de la enfermedad a la salud:

1. Mediante la acción ritual en la que la palabra tiene su manifestación en un gesto esotérico o bien la acción de la misma en el exoterismo.

2. La segun la situación es la transposición binaria de enfermedad a salud sin la acción de la palabra.

3. En todos los casos de curación es indispensable la fe o creencia de que realmente la enfermedad sale del cuerpo.

4. Los elementos rituales para una misma curación son muy variables, incluso en una misma aldea. En toda curación constato tres elementos estructurantes en la misma, los cuales son universales a todas las culturas: la persona, el tiempo y el espacio. Siendo la persona quien unifica los otros dos elementos que son el tiempo y el espacio. A ambos se les confiere una sacralidad específica dentro de una acción ritual determinada, y cuyo espacio puede variar desde su realización en la casa hasta en los cruceiros, girando la acción ritual en torno a símbolos representados. Pero en este trabajo también queda reflejada la acción ritual en torno a los símbolos figurados, siendo en la propia persona sanadora donde se ubica el tiempo y el espacio, realizando ésta la curación a distancia.

Ambas acciones simbólicas, tanto la representada como la figurada, me llevan a la reflexión de que somos seres simbólicos por excelencia y nuestra capacidad de representar y proyectar, mediante la fe, partiendo de la persona, permite la çreación de realidades en las que, como aquí describo, se transmuta en el cuerpo físico el paso de la enfermedad a la salud, sin «entrar» en la enfermedad, sino «invitáńdola» a salir del cuerpo.

\section{BIBLIOGRAFÍA CONSULTADA}

APALATEGI BEGIRISTAIN, J. (1978): Introducción a la historia oral. Kontuzaharrak (Cuentos viejos). Anthropos. 
BRIONES GÓMEZ, F. (1997): «El recurso a lo religioso en el itinerario terapéutico», pp. 197-219. Medicina popular e antropología da saúde. Simposio internacional en homenaxe a A. Fraguas Fraguas. Ed. Consello de Cultura Galega. Santiago, 1997.

DICCIONARIO NORMATIVO GALEGO-CASTELÁN (1998). Galaxia.

DOUGLAS, M. (1978): Símbolos Naturales. (Título original Natural Symbols-Exploration in Cosmology, 1970). Alianza Editorial.

GARCÍA-ORELLÁN, R.: Etnografia y relatos biográficos en el contexto cultural vasco y gallego 1998-1999 (sin publicar).

GARCÍA-ORELLÁN, R. (2001): Hacia el encuentro de mi anthropos: la muerte dinamo estructural de la vida. U.P.V./E.H.U.

GONDAR PORTSANY, M. (1999): Crítica da razón galega. Entre o nósmesmos e o nós-outros. Edit. Promocions culturais galegas.

GONZÁLEZ REBOREDO, X.M. (1999): «Mediadores en la Galicia urbana hoy», pp. 95-103. Religión y Cultura. Vol. I. Edit. Consejería de Cultura y Fundación Machado.

JUNG, C.G. (1994): Tipos Psicológicos (Título original Psychologische Types,1971). Edhasa. Barcelona.

LEACH, E. (1993): Cultura y Comunicación. La lógica de la conexión de los símbolos. (Título original: Culture and communication. The logic by wich symbols are connected 1976). Siglo XXI Editores.

LOUIS-VINCENT, T. (1993): Antropología de la muerte (Título original Anthropologie de la mort, 1975), Fondo de Cultura Económica.

LÉVI-STRAUSS, C. (1964): Mythologiques. Le cru et le cuit. Plon. Paris.

MOLINER, M. (1992): Diccionario de Uso del español. Gredos. 
MARIÑO FERRO, X.M. (1986): Medicina Popular II. Edicións Xerais de Galicia.

MONTAIGNE, M. (1979): Essais, livre II. Garnier-Flammarion, Paris.

ORAMAS DÍAZ, J. y RODRÍGUEZ LUIS, I. (1997): «La información científica y la medicina natural», http: bvs.sld.c4.

RISCO, V. (1962): «Etnografía. Cultura espiritual», Historia de Galicia. V. I dirigido por Otero Pedrayo. Editorial Nós. Buenos Aires.

RODRÍGUEZ LÓPEZ, J. (1974): Supersticiones de Galicia y preocupaciones vulgares. Editorial Calta. Lugo. Octava edición.

TABOADE CHIVITE, X. (1982): Ritos y Creencias gallegas. Sálvora.

VAN GENNEP, A. (1981): Les rites de passage. Éditions Picard. 